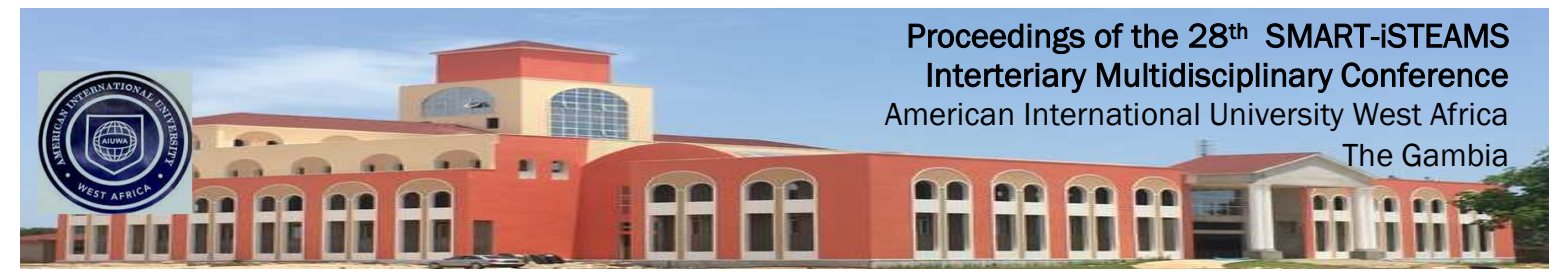

\author{
Full Qualitative Research Paper
}

\title{
Breeding Drug Abusers: Patent Medicine Vendors Experiences in Semi-Urban Areas of Ibadan, Nigeria
}

${ }^{1}$ Azeez Abolaji

2Azeez, Olubukola Yetunde 1Ayegboyin Matthew

1Department of Sociology, University of Ibadan

2Department of Accounting University of llorin

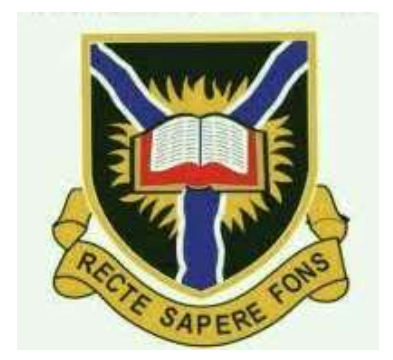

E-mails

abolaji2000@gmail.com

Phones

$+2348053079102$

\begin{abstract}
Indiscriminate drug use consistently constitutes a public health threat in developing countries including Nigeria. Therefore, the study explored PMVs' experiences to understand the socio-economic factors accountable for the demand and dispensation of multiple drugs to clients. The study was exploratory and qualitative. Through respondents determined survey (RDS), four patent medicine vendors and one pharmacist were recruited into the study for in-depth interviews. The PMVs had at least 7 years' experience and were aware of the restrictions guiding drugs they could sell. Although PMVs were prohibited from clerking clients lowincome households would constantly request for the multiple drugs especially to treat malaria and body pains. The clients reportedly wanted faster relief and cheaper therapy -as low as 100 naira i.e. $0.28 \$$. Also, such choices were made to treat under-five children however, the PMVs reportedly exercised caution on this. Consequent to that, the PMVs advised their clients to consult a physician. The PMVs believed their services and products were less expensive. Also, the vendors relied on experience, accommodation of local languages, follow up and referral to gain more patronage. The public should be exposed to the danger of consuming multiple drugs to promote a positive attitude towards the proper use of drugs.
\end{abstract}

Keyword: Indiscriminate drug use, treatment, Patent Medicine Vendors, Nigeria

Proceedings Reference Format

Azeez, A, Azeez, O.Y \& Ayegboyin, M. (2021): Breeding Drug Abusers: Patent Medicine Vendors Experiences in Semi-Urban Areas of Ibadan, Nigeria. Proceedings of the 28th iSTEAMS Intertertiary Multidisciplinary Conference. American International University West Africa, The Gambia. October, 2021. Pp157-167 www.isteams.net/gambia2021. DOI: 10.22624/AIMS/iSTEAMS-2021/v28N2P12 


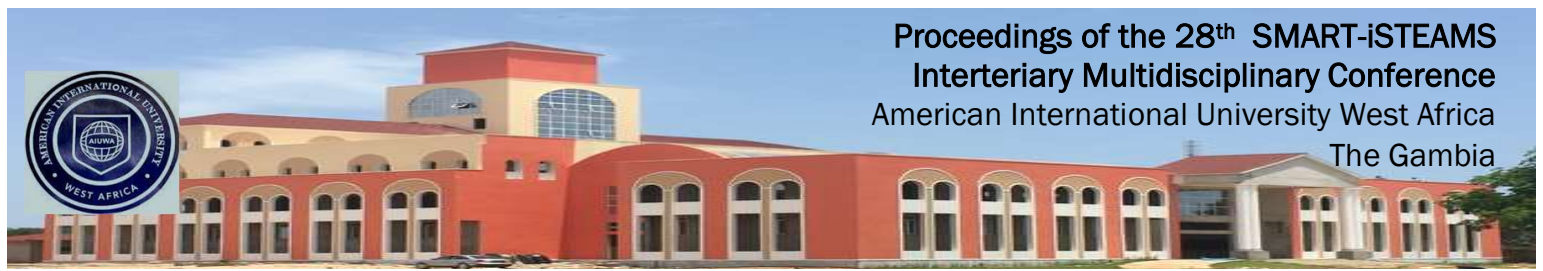

\section{BACKGROUND}

The rational use of drugs requires that patients receive medicines appropriate to their clinical needs, in doses that meet their own individual requirements, for an adequate period of time, and at the lowest cost to them and the community [1].

Historically, the definition of rational drug use stems from the process of professional clerking and patients adhering to the prescription of the physicians. The prescriptions are individual case-specific within a period of time. However, this is expected to be the patient. This standard remains relevant especially to the patients in resource-poor settings [2]. The description of the WHO focuses on the appropriateness of process, materials, situation and patients who consume the drug. The irrational use of drug occurs when any form of expected appropriateness is compromised regardless of the reason. Previous studies showed that irrational use of drugs often emanate from overuse and misuse of antibiotics and antidiarrheal for nonspecific childhood diarrhea or mild non-bacterial infection indiscriminate request for injections, multivitamins for malnutrition, crave for unnecessary expensive drugs and multiple or overprescription [3][4][5][6][7]. In 2018, UNODC presented how drug demand reduction could be achieved especially drug use that could result into morbidity and mortality in Nigeria. Much attention was placed on intentionally irrational drug users (IIDS) for non-medical purposes. Also, poly-drug use is one of the common characteristics of IIDS and multiple drugs users (MDS) for medical purpose. Just that the intentions are different and there are clear warnings or attentions on the latter.

In Nigeria, patent medicine vendors (PMVs) remain the mainstay of source and distribution of medications [11][4][12]. Although, the definition of the patent medicine vendors (PMVs) incorporated any person (without formal training in pharmacy) selling orthodox pharmaceutical products for profit-making. Yet the PPMVs with estimated 200,000 population are the first point of medical call [13] for 55\% of under-five caregivers and those who treated malaria in Nigeria [4][14][15][16]. In Kwara and Kogi states, the clients were less likely to be diagnosed since their financial capacity interfered with the decision to consult patent and proprietary medicine vendors [4]. Historically, apart from profit-making orientation, PMVs, serve as sources of advices and drug therapy [12] and supply drug dispensers, who learned the art through apprenticeship, to some pharmacy outlets [18]. Again, they exposed that community pharmacies had potential to improve health outcome at the grassroots. Although, the community pharmacy outlets are not significantly different from the PMV's since pharmacists are nocturnal proprietors who are usually engaged in other income-generating activities [18].

Undoubtedly, the ubiquitousness of PMVs has assisted in distributing ACTs to rural locations without formal heath care providers coupled with limited professional pharmacists and their services should be strengthened [23][11][4][18][19][12]. Thus, scholars have recommended that PMVs be trained to treat mild illnesses which people may not necessarily seek formal medical care [4]. However, PMVs (31.7\%) had health-related training especially as auxiliary nurses [19]. Perhaps, to them, the process of clerking is more of art and experience than formal training which prevented them from selling beyond over-the-counter (OTV) drugs. 


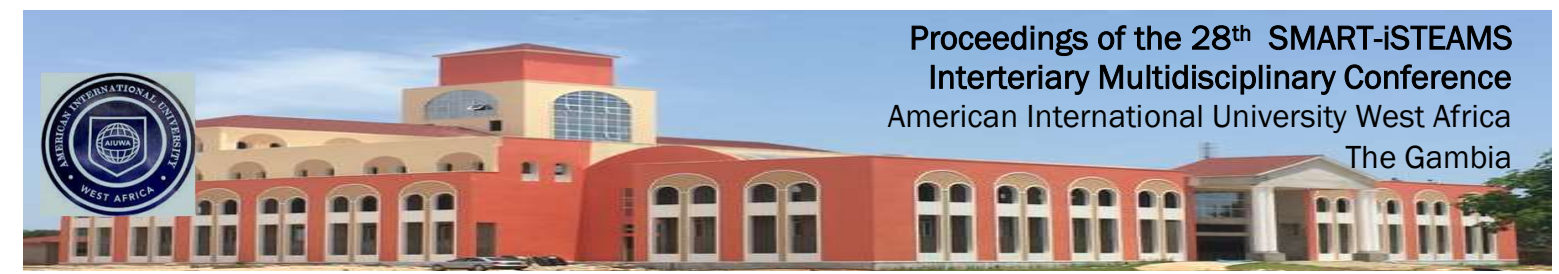

Drug use remains the last stage of the therapeutic consultation and the health professionals are responsible for appropriateness in prescription, dispensation and the injection of the prescribed drug. Thus, it is imperative to explore the nuances in experiences, services and contributions of patent medicine vendors to the injection of multiple drugs in semi-urban area of Oyo state.

\section{MATERIALS AND METHODS}

The study adopted qualitative approach through case study and grey literature to explore phenomenon with a view to gain in-depth insight into PMVs' experiences vis-à-vis socioeconomic factors accountable for the demand and dispensation of multiple drugs to clients in semi-urban of Ibadan. Selected cases were located in two local government areas (LGA), namely: Olunde area in Oluyole and Agbowo in Ibadan North LGAs. This centre could not meet the health needs of the large community. In fact, in few metres from the PHC, there are three PMVs around. Perhaps, the presence of the PMVs might be serving as easy-to-reach drug outlets to that immediate community. Previous studies only mentioned Agbowo description of the location [24] [25]. This study presented the experiences of PMVs in the location where there were limited pharmacist-owned outlets.

Four cases were selected through respondents' determined survey (RDS). This technique allowed the researchers to the recruitment of multi-level cases from a pool of cases. The first case (PMVs) was snowballed into the study and after the PMV duly consented to participate, an in-depth interview was conducted simultaneously. This technique allowed for consideration of the dynamics of cases in the case pool. The first case helped identified the second case and the second case helped identify the third case with little or no compensation. The sample of the multiple drugs was bought from the fourth case. Above all, the satisfaction of the basic inclusion criteria i.e. PMVs with at least 7 years experiences and located in the study area.

Research instruments for this study were a transect walk guide, in-depth interview guide and observation checklist. The triangulation of the instrument was to capture information which may not necessarily be reported due to omission or intention. Also, the combination aided better interpretation of the reported information from the cases. Data were collected and analysed.

\section{RESULT AND DISCUSSION}

\section{Meta-data}

Case \#1 is a married young female who was 29 years old before the study. Case \#1 had national certificate in education. She learnt patient medicine while in secondary school and proceed to auxiliary nursing afterwards. She has been in this business for 15 years altogether. Currently, she manages a PMV store while offering retail services in her community. Her store is a bit far away from the nearest pharmaceutical store which would require 15 minutes' drive. In her community she earned respect as a community nurse and PMV. Case \#2 shared similar characteristics with case \#1. Case \#2 was 36 years old married young man with Ordinary National Diploma. He was dynamic in selling both in retails and wholesales depending on the available market. 


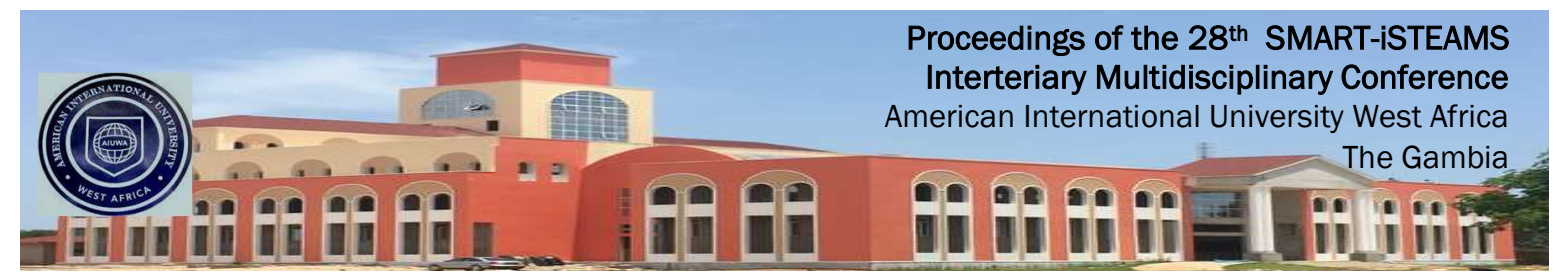

He had 10 years' experience in the business with a capital base not less than five hundred thousand naira. His store was in close proximity to the pharmacy which was within 1 minutes' drive in Olunde area.

Case \#3 was a middle aged (36 years) married woman, who had completed junior secondary school before learning PMV and nursing. In all, she had 20years experience in PMV retailing business. She was selling both drug and provisions which were the basic needs in her immediate environment. She believed that she had quality training than the present generation of apprentices from the present PMVs. Her store was a 3 minutes' drive to the nearest pharmaceutical store in Agbowo. Again, Case \#4 was a young woman with children from observation. She had a fuller store than Case \#3. Her children were learning the business from her. It was from her store that a sample of multiple drugs was bought to examine the content of the combination. Lastly, the pharmacist was a young professional female pharmacy who is currently working with in a pharmaceutical store in a metropolitan city. She had her master degree in pharmacy and certified professionally. She had 7 years' experience in the profession.

\section{Multiple drugs: PMVs Training experience}

Many apprentices will not complete the learning process based on the unbearable pressure from their bosses. Based on case \#3 there was no major difference from the manners and disposition of her boss. Again, case \#1 reported that her boss maintained her mentoring style until she gained her freedom. In another occasion, case \#1 recounted how her boss was ready to exert physical strength in order to ensure that punishment was served appropriately. Upon my return to the shop, I informed my sister that the wholesaler was not ready to collect the drugs and refund her money. Immediately, my sister picked up a cane, started chasing and cursing me. Case \#1 recalled more of instances when punishments were meted out for her rather than learning. In modern formal training in pharmacy at the tertiary level, there was no room for such physical and emotional abuse. The social construction of relationship precluded case \#1 from reporting such experiences to the law-enforcement agencies. Such experiences are limitedly reported [26]. Her experience in the medicine store was vividly captured in the Case 1.1.

\section{Multiple Drugs: Use and Emergence}

Case \#2 knew about different drugs where he was learning wholesales of patent medicine. He had contact with doctors and nurses whenever they came to patronise the business. To him, it is necessary for any medical apprentices proactively associate with the medical practitioners. Also, he demonstrated an inquisitive interest in knowing more about drugs and their uses. Whenever they came to buy I kept asking what this drug was working for ... and I would confirm whatever they told me in the leaflet of such drug. He did this severally. This showed that ability to read and comprehend is critical to dispensing drug correctly. Based on his attitude, he was exposed to what drugs could be combined to treat certain ailments especially when clients request for multiple drugs. He claimed that he understood the dynamics of multiple drugs combination. One will give active drug so that they will not come back and complain that the drug they bought yesterday did not work. I think nurse and doctors that we sell the drug to are vital in knowing what to combine (Case \#2/IDI/Male/36 years/OND/Mixed seller/10years experience/1minutes drive to pharmacy/Olunde/). 


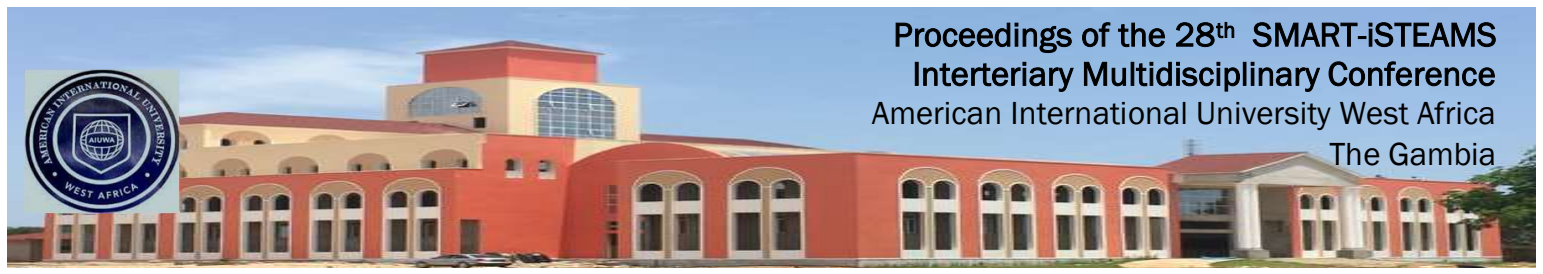

Case \#1 shared her first time experience in selling multiple drugs to a client. It was a normal experience. She highlighted that there was no significant difference in her expectation towards the outcome. She was conscious of the fact that unsatisfied client would return to complain that the last multiple drugs he/she used were ineffective. There was no negative report concerning the multiple drugs sold to the client. She continued to sell the combination.

The experience of Case \#3 was different since she learnt the patent medicine business around 1997. She maintained that multiple drugs were not a common practice among PMVs. She did not learn combination skills during her apprenticeship. After her graduation, demands for multiple drugs were often. She noticed that her colleagues were selling it with attendant financial returns. She did her cost/benefit analysis. She was able to identify the average price for the combination of multiple drugs. Also, she cost the prices of drugs that could function complementarily. In her first sale, she combined functionally-related and cost-effective drugs together. She ensures the majority of her clients who demanded multiple drugs complete the dosage for the major ailment such as malaria. Her decision was intentional since it was difficult to convince people to use a single drug for an illness.

The advice allowed her to follow up with her clients and got feedback from them. Also, affordability remained a major factor that determined whether a client would buy the complete dosage. This showed that clients who could not afford complete dosage for ailment, say malaria, were more likely to retreat malaria in quick succession. Thus the client that could afford it would be better off. Case \#3 displayed a higher level of confidence in the multiple drugs compared with case \#1, although both case \#1 and \#3 had nursing training. Case \#3 asserted that she was never afraid of negative outcomes because she gave her clients the right combination of multiple drugs.

\section{Multiple Drugs: People, Illness and Beliefs}

Case \#3 asserted that multiple drugs should not be the first point of call for patients. Patients or caregivers who found it difficult to spend out-of-pocket money birthed the use of multiple drugs. The assertion placed more emphasis on the financial capacity of the patients. Also, the patients/caregivers believed that multiple drugs would be more effective than a single drug. She mentioned that they would say stylistically 'would the single drug work'? This heralds the discussion around patients' belief and drug effectiveness using placebo effect discourse. All the cases maintained that those who opted for multiple drugs are mostly people with low income. Such income conditions predispose patients to substandard drugs or to continue to use drugs that are no longer recommended for general use such as chloroquine in order to earn effective treatment [27].

Since patients could not afford access to primary healthcare age of the patient does not count when there is an urgent need to care for a patient. For instance, case \#2 mentioned that some of his clients/caregivers had requested for multiple drugs to treat malaria for an under-five child. The PMV maintained that in such cases he would exercise caution in order to protect the interest of the child. However, in the bid to help the caregiver and make more sales, PMV could sell multiple drugs to the caregiver to treat the child. 


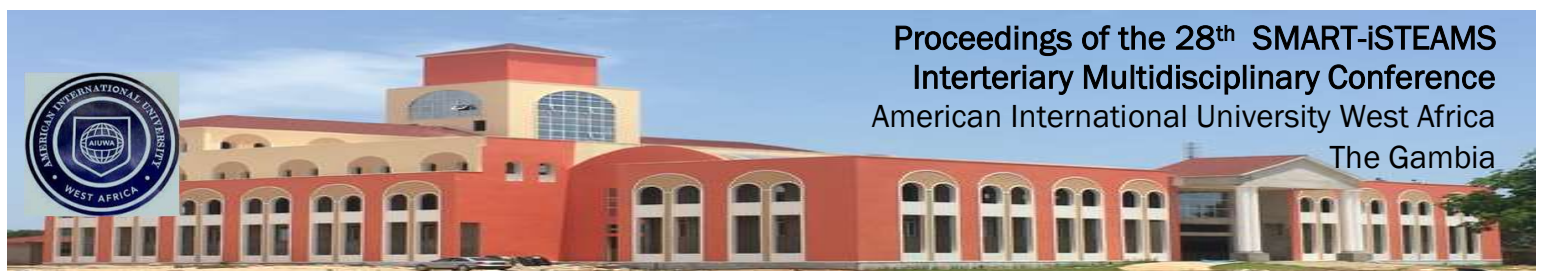

Case \#2 would advise the caregivers to source for more money to buy better drugs or take the child to the hospital for the necessary attention. One of the cases maintained that she would reduce the measure to be given to the child if need be. See Case 2.1.

The cases gave the occupational descriptions of people/patients who usually demand and use multiple drugs. They are people who are consistently engaged in strenuous jobs for a long duration daily such as hawking, bricklaying. The consistent exposure to strenuous activities could influence the belief that work engagement might not be responsible for body weakness. Similarly, the patients usually mentioned symptoms which include catarrh, headache and cold. With these symptoms, the patients believed there was a need to treat malaria. Consequent to that, the patient would request for multiple drugs for $1 b^{21}$ or Arariro' ${ }^{22}$. However, case \#3 maintained that patients were not aware that they were only exposed to cold. For case \#3, she would prescribe multiple drugs for patients to treat cold.

The PMVs and patients might be correct about their conclusions when patients explained their health conditions. Sometimes, patients may not be able to explain vividly their health situations to the PMVs. This gives room for the wrong prescription of multiple drugs for patients since the laboratory test is hardly carried out before and in the process of consulting PMVs. This shows the tendency for blind treatment in such outlets. Case \#2 emphasised that the patients would complain about body pain. To him, such complain displayed the tendency for patients to have come down with malaria for which patients would not want to use conventional pain relief drug. They would request for multiple drugs. Possibly the assumption would help curtail asymptomatic malaria [28]. The following quotation shared the experience of case \#1 to explain the kind of symptoms her client would always mention.

\section{Multiple Drugs: Preference, Time Dynamics, and Realities}

In a normal situation, case \#2 asserted that clients were expected to patronise pharmacists and PMVs after consulting physicians who would give a correct prescription. However, the state of the health care system in Nigeria and the level of poverty would not allow an average person to consult a doctor. Therefore, people consult the PMVs for multiple drugs for quick relief from illness. All cases reported that their clients consistently request for multiple drugs since they believed the combination was highly effective within a short time. The expectations of PMVs and their realities are expressed in Case 2.2.

Although following the preference for multiple drugs, case \#2 maintained that he usually prefers to sell drugs in sachet and give a good dosage but some people will insist that they should be given the multiple drugs. Like case \#3, case \#2 was aware that multiple drugs could be dangerous to health. His conclusion presented a business dilemma. He wanted to make more money and he did not want to sell the conventional request. 'I would give them but I do advise that if they want to use it they should use it in one-week interval because of the damage it could cause, especially the damage that such drugs could do to the liver. He was able to set caution in the succession of usage in order to prevent future negative impact on the clients. The question is what is the extent of damage per usage of multiple drugs? Was the caution recommended sufficient?

\footnotetext{
${ }^{21} \mathrm{Iba}$ is a Yoruba medical term to represent malaria

${ }^{22}$ Arariro means a severe body pain
} 


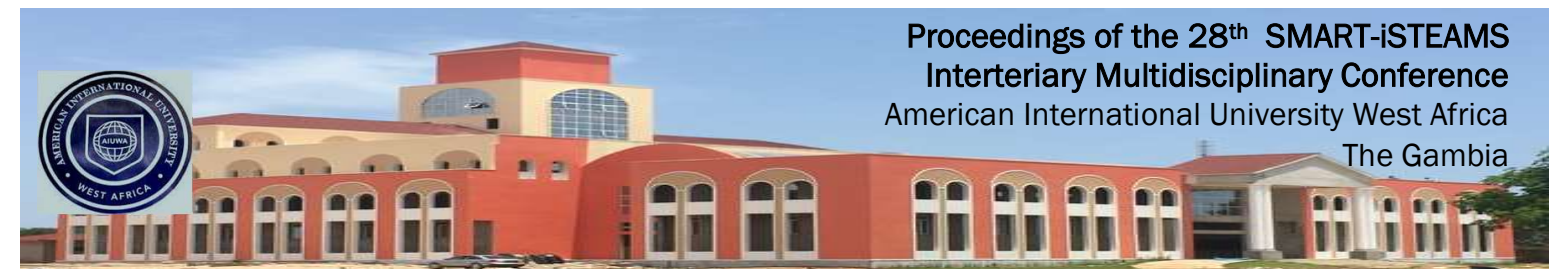

This would depend on the kind of drug combination a client was offered and individual's health idiosyncrasies. Clients would say it works fast. Case \#2 painted a scenario to buttress his point. It is like when $\mathrm{Mr} \mathrm{A}$ is experiencing headache then use Alabukun. One cannot compare $\mathrm{Mr} \mathrm{A}$ with another Mr B who used Boska for the same condition. Mr A would recuperate faster than Mr B (the person who used Boska). Case \#2 exposed that alabukun contained substances that could affect the kidney. Similarly, case 3 maintained that the sales of multiple drugs are detrimental to patients' health. This negative impact might not be felt immediately but the bodily damage would surface later in life.

Since there could be negative effect of using multiple drugs, case \#2 affirmed that anyone that wants to use multiple drugs should be at least 18years. Also, he exposed the need to refuse to sell to children of lower ages like 10 years, 12 years. Even though, their parents insisted, the PMVs were expected to give lesser dosage to the child. For instance, I would give a child one tablet where an adult would use two tablets (case \#2). He would exercise caution especially when a child is under five and obviously sick and refer them to next higher level clinic. After consulting the physician, he would sell drugs to them. And he stated clearly that PMVs are patent medicine vendors, not pharmacists

Time dynamics was identified as one of the factors that could enhance the effectiveness of multiple drugs. Only case \#3 mentioned that right timing in the use of drugs is important. It would enhance the effectiveness of the multiple drugs. She always encouraged her clients to use their drugs at the appropriate time. More specifically, the clients should use their multiple drugs by $7.30 \mathrm{pm}$.

Case \#2 pointed out that the perceived cost of drugs and services usually influence the preference for a particular medicine outlet. Previously, the cost of drug in the pharmacy shops was higher, but now their prices are coming down like that of the patent medicine vendors. Presently, for instance, PMVs sell the ferrous for 1600 naira while in pharmacy a patient can buy at 1500 naira since there is influx of pharmacies. The prices of drugs from pharmacists are now less expensive. The pharmacies store sometimes sell drugs lesser than the amount PMVs sell the drug. However, a study reported that high patronage was recorded among PMVs based on the cheapness of their drugs [4]. Case \#2 identified that the size of the population in an environment would determine the market prices of many drugs. What usually makes prices high is the number of people in a community. Case \#3 had a dissimilar orientation about the prices of drugs in the pharmacies.

To her, drugs in pharmacy are more expensive by experience. Case \#3 ran out of a particular medicine and decided to patronise a pharmacy on behalf of a client in order to keep the client's patronage. Case \#3 added more money to be able to purchase the drug. Possibly, the physical organisation and the recruitment of staff possibly increase the average cost of drugs in the pharmacy. Also, case \#3 exposed that patients' time is usually wasted in pharmacy based on their attitude to work and patient. This is possible since some pharmacies operate through attendants. Thus the service of a pharmacist is by proxy [18]. Although the pharmacists are professionals, they do not train individuals except in formal settings. In fact, case \#3 asserted that many of the attendants in the pharmacies are trainees from PMVs. 


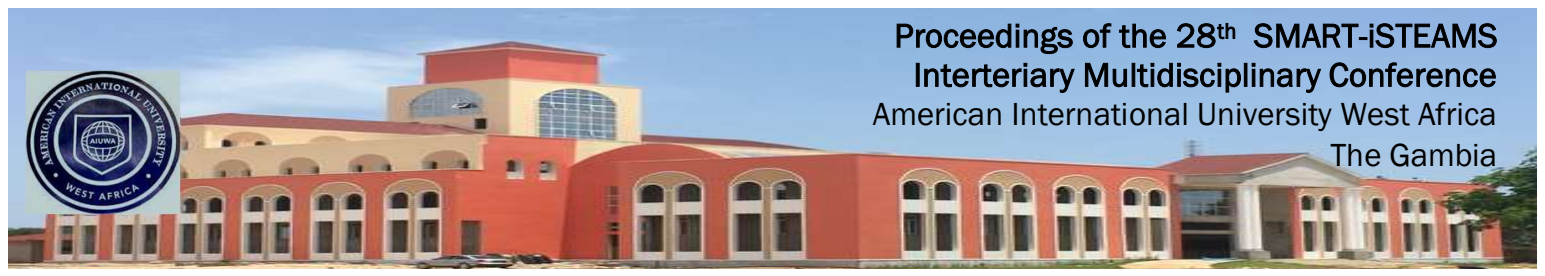

Multiple Drugs Use: Substandard Drugs and Abuse Tendencies

One tempting justification for the requests, sales and consumption of multiple drugs among PMVs and their clients is the production of counterfeit drugs. This could lead to the abuse of unsuspected drugs. Previous studies have not identified the tendency to demand for multiple drugs due to non-standardised drugs [3][4][5][6][7]. One of the cases, who were selling in retails and wholesales, identified the manipulations of some of the pharmaceutical companies which produced substandard drugs. The companies reduced the milligrams in their drugs possibly to earn more profit. The middlemen in the chain of distribution are involved while substandard products were branded to resemble original products. Presently, pharmaceutical companies have initiated check on expensive drug i.e. dial a code and get drug authentication. However, such a check is limited to literate clients who are ready to follow the process. Also, this check might not be possible during emergencies.

This limitation is well pronounced among clients without formal education. Case \#2 asserted that pharmacies are not exempted from the tendencies to procure substandard drugs as the PMVs and pharmacists are patronising the same market since such products are relatively cheaper. Again, case \#2 asserted that pharmacists did not have any special way of discovering a substandard drug. The question that needs an answer is to understand how patients who consult pharmacists cope with their health conditions until their complete recuperation. He recommended major research or ethnographic observation of multiple drug sellers. He later submitted that their business was becoming riskier. The discussions with all cases in this study showed that the PMVs could not link the production of substandard drugs to the incessant requests for multiple drugs from their clients to earn fast recovery. Thus the purchase of the multiple drugs at the whims of clients who believed that single drug would not help their health condition tended toward the abuse of the drugs. See Case 2.3.

The PMVs were aware of the prescription on codeine and tramadol which were usually abused by people. Case \#2 was able to mention some of the brands of drugs that contained prohibited content. He further maintained that the sales of such products would be sanctioned when caught by the regulatory agency in Nigeria. Again, he highlighted some items that he would not sell to non-medical professionals. To him, the professionals must identify themselves before they can transact business with him. Potentially, the check would prevent unwholesome distribution of drugs and other medical materials

\section{Multiple Drugs Use: the Challenges of PMVs}

All the cases of PMVs identified various sources of concern in the patent medicine business. Specifically, case \#3 asserted that the new set of PMVs from the apprenticeship remains the major sellers of multiple drugs. They do not really understand the work perfectly or they are driven by business profit. Sometimes, the urge made them sell an unwholesome combination of drugs just to make more financial fortune for them. Also, the PMVs mentioned intra-business struggles. The internal rancour manifested in envy. Co-PMVs were allegedly accused of reporting other PMVs to the police that some PMVs were dealing in illegal drugs or medical materials. These usually affected PMVs who enjoyed high patronage. Again, case \#3 reported that there was no way PMVs can escape the accusation from the law enforcement agencies. For example, Case \#2 maintained that law enforcement agencies would disturb them consistently the financial loss accrued to accusation ranged between 5000 -35000 naira based on experience. 


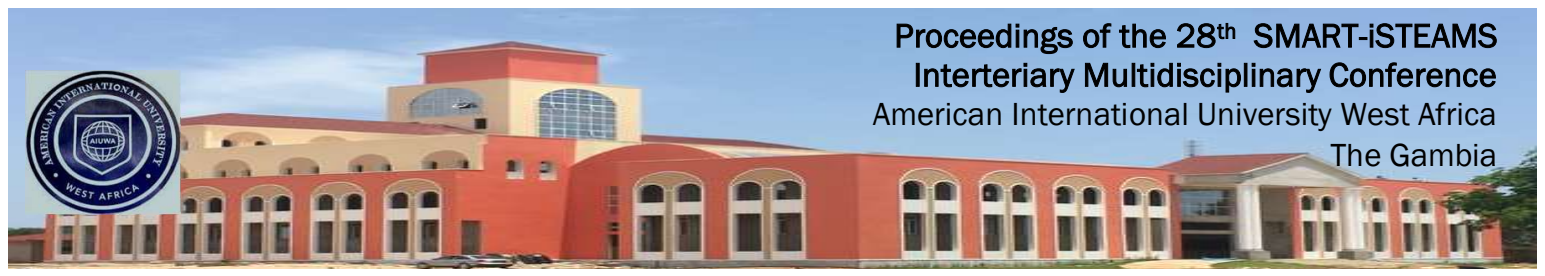

Multiple Drugs: PMVs Knowledge, Skills and Combination Dynamics

Case \#2 asserted that some of their colleagues sold some dangerous combinations perhaps innocently. All cases did not deny selling the multiple combinations. They were fast to give examples of the combination of drugs some of their co-PMVs would sell in some instances. However, cases \#1, 2 and 3 maintained that they understood how to combine multiple drugs for effectiveness. Most of them mentioned that one analgesic, one antibiotic and at least one blood capsule would be appropriate to treat malaria or severe body pain. None of them mentioned antimalarial drug while dispensing multiple drugs to treat malaria. Case \#2 and 3 were conscious not to mention more than pain relief or analgesia. All the PMVs (cases) confidently asserted that those combinations were highly effective. But for case \#2, he asserted that he cannot combine two drugs with paracetamol content. When I cut one drug with paracetamol, if it is for malaria, one will give them amoxicillin. I will give Felvin, with blood tonic. Consequently, the situation portrays that patients in such locations might be treating bacterial infections while the PMVs and their clients would assume they were combating malaria. This was contrary's recommendation in proper drug dispensation. The following extract described multiple drugs some of the PMVs would sell to their clients for severe body pain [2].

Plate 1 presents typical multiple drugs bought from one of the selected PMVs (case \#4) in Agbowo. The multiple drugs were meant for the treatment of malaria. It contained a combination of drugs namely using top-down sequence 1. Diclofenac, 2. Boska, 3. Felvin, and 4. Blood capsule. See Case 4.1. The drugs were presented to a certified pharmacist with about 7years experience to discuss the categories of these drugs and the likely health outcomes that could emanate from the injection of the multiple combinations. The pharmacist exposed that the 1-3 of the drugs belonged to the analgesic (NSAIDs) family while drug \#4 is a multivitamin. One of the first three drugs can be used at once by a patient. The use of the multiple drugs as listed in plate 1 is dangerous to human health, since such patient has exceeded the daily milligrams limit of the analgesics. Similarly, the health risk for such unhealthy drug behaviour was identified [9]. Specifically, anyone that injects these drugs is more likely to suffer internal organ injuries. This would result in malfunctioning of the kidney and liver. The standard of clerking patients before drug prescription should be done by certified professionals even in poor-resource settings [2].

\section{CONCLUSION}

Generally, multiple drugs are sold by the patent medicine vendors through which they felt more relevant to their communities than the pharmacies. The emergence and sales of multiple drugs emanate from its demand which was powered by low income and belief about the inability of a single drug to be effective for ill-health. Apart from income and belief system of the patients/caregivers, occupational dimension was established and people who engaged in strenuous jobs demanded for the multiple drugs. All the cases claimed expertise in the sale of multiple drugs but a typical multiple drugs weakened their claims i.e. case4\#. The wrong combination of multiple drugs could damage internal organs. Although the PMVs had training which should have helped, the training could not achieve its purpose based on the process and how PMVs perceived the organisers. Thus, sensitization of the public about the dangers of multiple drugs through mass media coupled holistic paradigmatic shift from conventional training to goal-driven training of PMVs to sustain their health relevance especially in areas with limited pharmacies. 


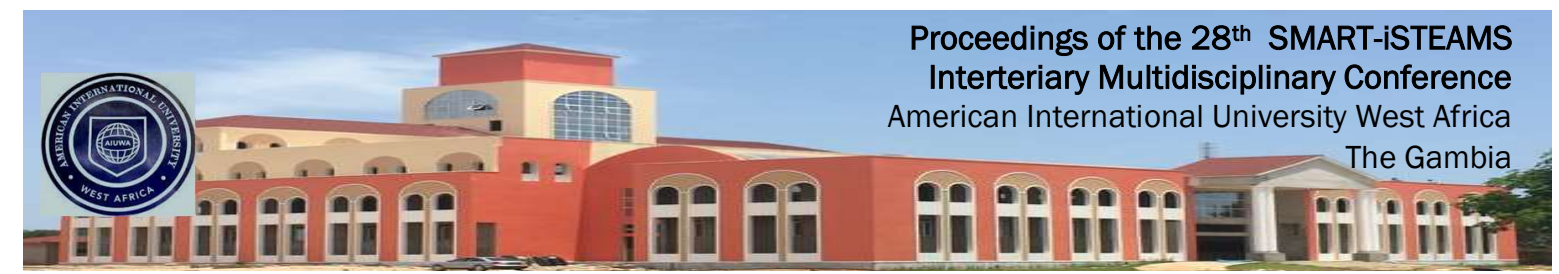

\section{Reference}

1. WHO, 2012. The Pursuit of Responsible Use of Medicines: Sharing and Learning from Country Experiences WHO/EMP/MAR/2012.3. Available online: https://www. who.int/medicines/publications/responsible_use/en/ Accessed on 4th June, 2019

2. Okeke, T.A., and Okeibunor, J.C. (2010). Rural-urban differences in health-seeking for the treatment of childhood malaria in south-east Nigeria. Health Policy. Apr95(1):62-8. http://dx.doi.org/10.1016/j.healthpol.2009.11.005 PMID:20004038

3. Federal Ministry of Health (2012) National implementation guidelines for integrated community case management of childhood illness in Nigeria. Abuja

4. Liu, J., Isiguzo, C., Sieverding, M., (2015) Differences in malaria care seeking and dispensing outcomes for adults and children attending drug vendors in Nasarawa, Nigeria. Trop Med Int Health.20(8):1081-92. http://dx.doi.org/10.1111/tmi.12520 PMID:25877471

5. Awor, P., Wamani, H., Tylleskar, T., Peterson, S. (2015) Drug seller adherence to clinical protocols with integrated management of malaria, pneumonia and diarrhoea at drug shops in Uganda. Malar J.14(1):277. http://dx.doi.org/10.1186/s12936-015-0798-9 PMID:26178532

6. Society for Family Health (2014). Report on the pilot study on feasibility of malaria diagnosis using malaria RDT by PPMVs in Nigeria. Abuja:

7. Isiguzo, C., Anyanti, J., Ujuju, C., Nwokolo, E., De La Cruz, A., Schatzkin, E., et al. (2014) Presumptive treatment of malaria from formal and informal drug vendors in Nigeria. PLoS ONE.9(10):e110361.http://dx.doi.org/10.1371/journal.pone.0110361 PMID:25333909

8. United Nations Office on Drugs and Crime (UNODC) (2018) Drug Use in Nigeria. United Nations Office on Drugs and Crime, Vienna Austria. Available online: www.unodc.org. accessed 29/06/2019.

9. Awosan, K. J., Ibitoye, P. K., Abubakar, A. K. (2018) Knowledge, risk perception and practices related to antibiotic resistance among patent medicine vendors in Sokoto metropolis, Nigeria. Niger J Clin Pract 21:1476-83. Available online: http://www.njcponlin e.com/text.asp?2018 21/11/1476/245187 Accessed on: 18 Aug, 2019

10. Obukohwo, E. O., Olele, E. H., and Buzugbe, P. N. (2018) Assessing Efficiency in the Pharmaceutical Sector of Nigeria CBN Journal of Applied Statistics. 9 (2) 131-148

11. Durowade, K. A., Bolarinwa, O. A., Fenenga, C. J., Akande,T. M. (2018) Operations and Roles of Patent and Proprietary Medicine Vendors in Selected Rural Communities in Edu Local Government Area, Kwara State, North-Central. Journal of Community Medicine and Primary Health Care. 30 (2) 75-89

12. Nigeria. Demographic and Health Survey (2013) Abuja and Rockville: National Population Commission and ICF International 2014. Available from: http://dhsprogram.com /pubs/pdf/FR293/FR293.pdf [cited 2015 Dec 12].

13. Onyeneho, N.G., and Chukwu, J.N. (2010) Is there a role for Patent Medicine Vendors in Tuberculosis Control in southern Nigeria. Health Popul Nutr 28(6): 567-577

14. Brieger, W.R., Osamor, P.E., Salami, K.K., Oladepo, O., and Otusanya, S.A. (2004) Interactions between patent medicine vendors and customers in urban and rural Nigeria. Health Policy Plan 19: 177-182 2.

15. Bames J, Chandani T, Feeley R. (2008) Nigeria Private Sector Health. Bethesda, MD: Private Sector Partnerships-One Project, Abt Associates Inc. 


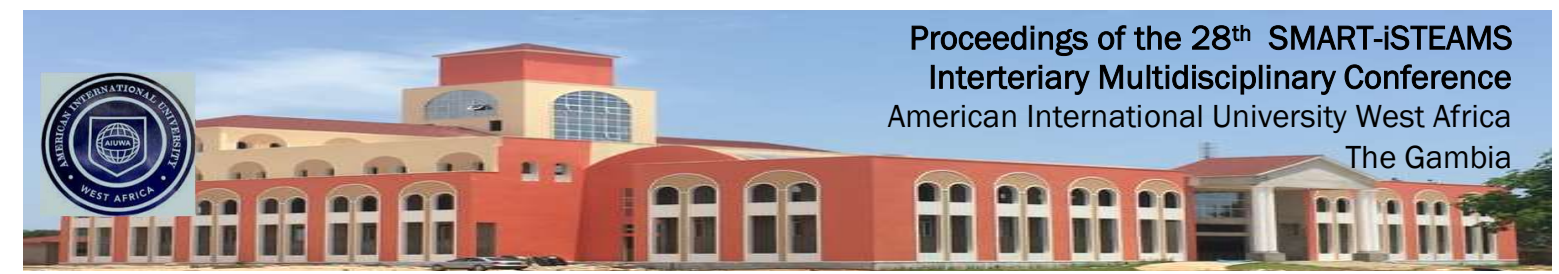

16. National Population Commission, ICF Macro (2009). Nigeria Demographic and Health Survey 2008. Abuja: National Population Commission and ICF Macro .

17. National Bureau of Statistics, UNICEF, UNFPA. (2013) Nigeria Multiple Indicator Cluster Survey 2011: Main Report. Abuja: NBS, UNICEF and UNFPA.

18. Ogbonna B. O., Ejim C.E., Ikebudu C.C., Uzodinma S.U., and Orji, C.E. (2015) Pharmaceutical care and community pharmacy practice in nigeria grappling with the frontier. European Journal of Pharmaceutical and Medical Research. 2(7), 33-42. Available online: www.ejpmr.com. Accessed on: 17/08/2019.

19. Oyeyemi, A.S., Ogunnowo, B.E. and Odukoya, O.O. (2014) Patent Medicine Vendors in Rural Areas of Lagos Nigeria: Compliance with Regulatory Guidelines and Implications for Malaria Control. Tropical Journal of Pharmaceutical Research 13 (1): 163-169 Available online at http://www.tjpr.org http://dx.doi.org/10.4314/tj pr.v13i1.23

20. Federal Ministry of Health, National Malaria and Vector Control Division, Abuja-Nigeria (2005). National Antimalarial Treatment Guidelines.

21. Pharmacists Council of Nigeria (PCN) (2003). Guidelines on the issuance of Patent and Proprietary Medicines Vendor's License

22. Amin, A.A, Snow, R.W., (2005) Brands, costs and registration status of antimalarial drugs in the Kenyan retail sector. Malar J 4: 36.

23. Ma'aji, H. U., Khan, F., Shuaibu, A., Abdu-Aguye, S. N., Mohammed, M (2018) Assessment of hospital pharmacy services in North-western Nigeria. Nigerian Journal of Pharmaceutical Sciences. 17(1)

24. Azeez, A. and Salami, K.K. (2018) Giving Back to the Elderly: Cross-Cultural Construction of Befitting Burial for the Dead in Nigeria. Journal of Population Ageing, https://doi.org/10.1007/s12062-018-9231-9

25. Azeez, A. and Isiugo-Abanihe, U. C. (2017) Sociocultural Context and Determinants of Treatments for Hemorrhoids among the Nigerian Police, Oyo State Command. Journal of Social, Behavioral, and Health Sciences. 11.1:31-46 Doi: 10.5590/JSBHS .2017.11.1.02

26. Azeez, A. (2016) Gender-based Violence Experiences and Reactions in Ibadan Metropolis Nigeria. Advances in Multidisciplinary Research Journal 2.2:147-156.

27. Oladipo, O. O., Wellington, O. A. \& Sutherland, C. J. (2015). Persistence of chloroquineresistant haplotypes of Plasmodium falciparum in children with uncomplicated Malaria in Lagos, Nigeria, four years after change of chloroquine as first-line antimalarial medicine. Diagnostic Pathology. DOI: 10.1186/s13000-015-0276-2

28 . Dokunmu, T. M., Adjekukor, C. U., Yakubu, O. F., Bello, A. O., Adekoya, J. O., Akinola, O., Amoo, E. O. and Adebayo, A. H. (2019) . Asymptomatic malaria infections and Pfmdr1 mutations in an endemic area of Nigeria Malar $J$ 18:218 . Available online https://doi.org/10.1186/s12936-019-2833-8. Accessed on 25/09/2019 